\title{
Effect of Low Dose Aspirin in Low Risk Pregnant Ladies with Abnormal Uterine Artery Doppler Results, and the Evaluation of Maternal and Fetal outcomes: A Randomized Clinical Trial
}

\author{
Parzhin Jalal Ali \\ Obstetrics and Gynecology Department \\ Sulaimani Maternity Teaching Hospital \\ Sulaimani/Iraq \\ parzheen.jalal@gmail.com
}

\author{
Chro Najmaddin Fattah \\ Obstetrics and Gynecology Department \\ School of Medicine/University of Sulaimani \\ Sulaymaniyah/Iraq \\ chrofattah@yahoo.co.uk
}

\begin{abstract}
This study aimed to identify the effect of low dose aspirin administration in low risk pregnant ladies who have abnormal uterine artery Doppler results. Patients and Methods: A randomized clinical trial was performed on 50 pregnant ladies ( $\geq 16$ weeks of gestation) in Sulaymaniyah Maternity Teaching Hospital during January 2017 to January 2018. The participants were randomly enrolled into two groups; the participants in the first group were given $100 \mathrm{mg}$ of aspirin tablet each but the other group was given nothing. Results: Preeclampsia was significantly (P-value of <0.001) less in the aspirin group as compared to the other group (16\% and $40 \%$ respectively). The pulsatility index (PI) was not significantly different in both the groups $(P-$ value $=0.69)$, but resistance index (RI) was significantly lower in the aspirin group (P-value of <0.001). Conclusion: Doppler study of the uterine artery at 16 weeks or higher in low risk pregnant women appears to be useful as a screening test and low dose of aspirin therapy at early stage of pregnancy will decrease the incidence of preeclampsia.
\end{abstract}

Keywords: Aspirin, Doppler ultrasonography, Low risk pregnancy, Preeclampsia, Pulsatility index (PI), Resistance index (RI).

\section{INTRODUCTION}

Platelet lifespan was assessed by a non-radio isotopic method that involves measuring the serum concentration of thromboxane $\mathrm{B}_{2}\left(\mathrm{TXB}_{2}\right)$. Furthermore, this compound is the stable metabolite of thromboxane $\mathrm{A}_{2}\left(\mathrm{TXA}_{2}\right)$, and is produced maximally by platelets during clotting. Aspirin irreversibly acetylates the platelet cycle-oxygenase enzyme and this prevents thromboxane production [1]. This property of low-dose aspirin has been the rationale for its use as a therapy to decrease the occurrence of preeclampsia in at-risk women. Furthermore, platelets have a very short lifespan and this may have been even shorter during pregnancies. In individuals with normal platelet lifespan, one low-dose aspirin tablet $(75 \mathrm{mg})$ eliminated $50 \%$ of platelet function within 24 hours and $90 \%$ inhibition was achieved after the administration of a second low-dose aspirin tablet [2].
Preeclampsia, that complicating $2-8 \%$ of all pregnancies, is a major cause of maternal morbidity [3]. Moreover, it is a serious systemic condition and accounts for more than 50000 maternal deaths annually worldwide [4]. The origin of the disease is thought to be complex interaction of pregnancy including specific immunological and vascular adaptation, constitutional factor as well as dysfunctional trophoblastic development, and impaired placentation which is thought to occur between eight and 18 weeks of gestation [5]. Preeclampsia is caused by the defect of fetal-maternal circulation which is associated with impaired trophoblastic invasion that leads to lack of adequate response of mother vessels to implantation [6].

Uterine artery Doppler screening is a screening program for prediction of Preeclampsia. Color flow mapping is used to identify vessels, either transabdominally at the apparent crossover with the external iliac artery, or transvaginally lateral to the uterine cervix at the level of the internal cervical os [7]. In addition, uterine artery impedance is affected by heart rate, antihypertensive drugs, menstrual cycle, and chronic hyperandrogenism in the polycystic ovarian syndrome. Resistance to blood flow within the uteroplacental circulation is transmitted upstream to the uterine arteries and can be measured as an increased pulsatility index (PI) or resistance index (RI). Uterine artery PI and RI values decrease with increasing gestational age, a change that is thought to be secondary to decrease in impedance in uterine vessels following trophoblastic invasion [8-9]. Lowdose acetylsalicylic acid therapy inhibits thromboxane more than prostacyclin production, and thereby protects against vasoconstriction and pathologic blood coagulation in the placenta [10]. Moreover, groups have investigated low-dose aspirin as a therapeutic intervention for preeclampsia, but the value of this treatment remains controversial. While some randomized controlled trials have shown no, or minimal, benefit from this intervention [11-13], recent meta-analyses have suggested that, provided treatment 
is started at an early gestational age ( $<16$ weeks), there is a reduction in early-onset preeclampsia and that is associated with a reduction in the prevalence of perinatal death and morbidity [13]. Low dose aspirin has shown benefits in very high risk population by reducing the incidence of preeclampsia for about $70 \%$ and intrauterine growth restriction by 50\% [14]. Aspirin does not, however, appear efficacious among low or moderate risk populations [15-16], although most patients who develop preeclampsia or intrauterine growth restriction are either nulliparous or multiparous without any relevant history. It is therefore essential to find a way to screen women who could benefit from preventive treatments.

The uteroplacental artery Doppler flow velocity waveform (UAD) performed between 20 and 24 weeks of gestation has a good predictive value for intrauterine growth restriction and preeclampsia in general population, especially among nulliparous. It also has the advantage of being simple to perform, reproducible and non-invasive [17]. Furthermore, three trials have tested aspirin administration against a placebo for women with abnormal uterine artery Doppler results and two observed beneficial effects [18].

In this study, we want to know the effect of low dose aspirin on low risk pregnant women at the gestational age of 16 weeks or higher and who are with abnormal uterine artery Doppler results. In addition, we also want to evaluate the maternal and fetal outcomes including prevention of intrauterine growth restriction and development of preeclampsia until 36 weeks of gestation.

\section{PATIENTS AND METHODS}

We performed a randomized clinical trial on 50 pregnant ladies and divided them into two groups; 25 women in each group. The first group was using $100 \mathrm{mg}$ tablet of aspirin and the second group was using nothing. Moreover, the study was performed in the Sulaymaniyah Maternity Teaching Hospital during January 2017 to January 2018. Therefore, ethical approval was obtained from the scientific committee of the Sulaymaniyah Maternity Teaching Hospital.

The inclusion criteria were all singleton prime and multigravida healthy low risk pregnant women with abnormal uterine artery Doppler results at or after 16 weeks of gestation. Moreover, the age of the participants ranged between 18 and 35 years old. Furthermore, the exclusion criteria were twin pregnancy, pregnancy complicated by medical disease, past and current poor obstetrics history, past and current history of Hypertension, gestational diabetes and other medical diseases.

Patients were selected based on the inclusion and exclusion criteria. Furthermore, the objectives and implementation of the study was explained to all the participants and their written consents were obtained. Then, the demographic features including maternal and gestational ages, parity and gravidity were recorded.

Gestational age was calculated based on the last menstrual period (LMP) and/or early ultrasound for all prime parous and multiparous women in addition to the routine prenatal ultrasound for the evaluation of the pregnancies. Moreover, abdominal ultrasound was performed to evaluate uterine artery by using a sagittal view of the uterine cervical canal, including the internal os, and its location was identified.
Then, the transducer was moved slowly from one side to the other side and simultaneously color Doppler was also used to identify the uterine artery on each side parallel to the surface of the cervix at the level of the internal os.

Pregnant women with abnormal findings in the uterine artery Doppler were randomly enrolled into one of the two groups; patients in the first group were treated by $100 \mathrm{mg}$ daily dose of aspirin till 36 weeks of gestation but the other group did not receive any drug. Moreover, all the routine prenatal examinations including checking blood pressure and protein urea were examined in all the participants at or beyond 16 weeks of gestation.

We used IBM SPSS Statistics version 20 to calculate our data. Moreover, a P-value of $\leq 0.05$ was considered statistically significant, and a P-value of $<0.001$ as statistically very highly significant.

\section{RESULTS}

The demographic characteristics of study population were summarized in (Table1).

Table 1: demographic features of the participants with no significant difference between the groups

\begin{tabular}{|l|c|c|c|}
\hline Variables & $\begin{array}{c}\text { Aspirin } \\
\text { group }\end{array}$ & $\begin{array}{c}\text { Non-aspirin } \\
\text { group }\end{array}$ & $\begin{array}{c}\text { P- } \\
\text { value }\end{array}$ \\
\hline $\begin{array}{l}\text { Age in year (Mean } \\
\pm \text { SD) }\end{array}$ & $28.2 \pm 4.4$ & $26.8 \pm 3.8$ & 0.73 \\
\hline $\begin{array}{l}\text { BMI in kg/m } \\
\text { (Mean } \pm \text { SD) }\end{array}$ & $23.8 \pm 1.8$ & $23.9 \pm 1.2$ & 0.63 \\
\hline Primiparity (\%) & $7(28 \%)$ & $13(52 \%)$ & 0.25 \\
\hline Multiparty (\%) & $18(72 \%)$ & $12(48 \%)$ & 0.25 \\
\hline $\begin{array}{l}\text { Number of } \\
\text { pregnancy (Mean } \\
\pm \text { SD) }\end{array}$ & $2.4 \pm 1.2$ & $2 \pm 1.2$ & 0.26 \\
\hline $\begin{array}{l}\text { Systolic blood } \\
\text { pressure in mmHg } \\
\text { (Mean } \pm \text { SD) }\end{array}$ & $122 \pm 25.2$ & $125.2 \pm 26.2$ & 0.29 \\
\hline $\begin{array}{l}\text { Diastolic blood } \\
\text { pressure in mmHg } \\
\text { (Mean } \pm \text { SD) }\end{array}$ & $69.2 \pm 12.6$ & $79.2 \pm 18$ & 0.28 \\
\hline $\begin{array}{l}\text { Gestational age in } \\
\text { week (Mean } \pm \\
\text { SD) }\end{array}$ & $38 \pm 1.4$ & $38.3 \pm 1.3$ & 0.71 \\
\hline BMI Body Mass & & & \\
\hline
\end{tabular}

BMI = Body Mass Index; SD = Standard Deviation

Table 2: the outcomes of pregnancy in both groups.

\begin{tabular}{|c|c|c|c|}
\hline $\begin{array}{c}\text { Pregnancy } \\
\text { outcomes }\end{array}$ & $\begin{array}{c}\text { Aspirin } \\
\text { group }\end{array}$ & $\begin{array}{c}\text { Non-aspirin } \\
\text { group }\end{array}$ & $\begin{array}{c}\text { P- } \\
\text { values }\end{array}$ \\
\hline Mild PET & $3(12 \%)$ & $7(28 \%)$ & $<0.001$ \\
\hline Moderate PET & $0(0 \%)$ & $1(4 \%)$ & $<0.001$ \\
\hline Severe PET & $1(4 \%)$ & $2(8 \%)$ & $<0.001$ \\
\hline IUGR (PET) & $1(4 \%)$ & $2(8 \%)$ & $<0.001$ \\
\hline $\begin{array}{c}\text { IUGR } \\
\text { (normal) }\end{array}$ & $0(0 \%)$ & $0(\%)$ & $<0.001$ \\
\hline Reduced liquor & $1(4 \%)$ & $0(0 \%)$ & $<0.001$ \\
\hline Fetal demise & $0(0 \%)$ & $0(0 \%)$ & - \\
\hline
\end{tabular}

IUGR = Intra-Uterine Growth Retardation; PET = Preeclampsia 
Table 3: the ultrasound outcome in both groups.

\begin{tabular}{|l|l|l|l|}
\hline Ultrasound outcomes & Aspirin group (mean \pm SD) & Non-aspirin group (mean \pm SD) \\
\hline PI (PET) & $2.78 \pm 0.32$ & $2.9 \pm 0.62$ & 0.69 \\
\hline PI (normal) & $1.39 \pm 0.09$ & $1.40 \pm 0.14$ & 0.69 \\
\hline RI (PET) & $0.68 \pm 0.01$ & $0.69 \pm 0.04$ & $<0.001$ \\
\hline RI (normal) & $0.49 \pm 0.04$ & $0.52 \pm 0.04$ & $<0.001$ \\
\hline
\end{tabular}

PET = Preeclampsia; PI = Pulsatility index; RI = Resistance Index; SD = Standard Deviation.

Table 4: the fetal outcomes of both groups.

\begin{tabular}{|c|c|c|c|c|c|}
\hline \multicolumn{3}{|l|}{ Fetal outcomes } & Aspirin group & Non-aspirin group & P-values \\
\hline \multicolumn{3}{|c|}{ Infants' body weight $(\mathrm{kg})($ Mean $\pm \mathrm{SD})(\mathrm{PET})$} & $2.23 \pm 1$ & $2.3 \pm 0.85$ & $<0.001$ \\
\hline \multicolumn{3}{|c|}{ Infants' body weight $(\mathrm{kg})($ Mean $\pm \mathrm{SD})($ normal $)$} & $3.4 \pm 0.42$ & $3.4 \pm 0.37$ & $<0.001$ \\
\hline \multicolumn{3}{|l|}{ Fetal demise } & $0(0 \%)$ & $0(0 \%)$ & $<0.001$ \\
\hline \multirow{4}{*}{$\begin{array}{l}\text { APGAR } \\
\text { (frequency) }\end{array}$} & \multicolumn{2}{|c|}{ Normal (10) } & $22(88 \%)$ & $20(80 \%)$ & \multirow{4}{*}{$<0.001$} \\
\hline & \multirow{3}{*}{ Low } & 6 & $0(0 \%)$ & $1(4 \%)$ & \\
\hline & & 7 & $2(8 \%)$ & $2(8 \%)$ & \\
\hline & & 8 & $1(4 \%)$ & $2(8 \%)$ & \\
\hline \multicolumn{3}{|c|}{ Admission to NCU for $>6$ hours (frequency) } & $1(4 \%)$ & $2(8 \%)$ & $<0.001$ \\
\hline
\end{tabular}

kg = Kilogram; NCU = Neonatal Care Unit PET = Preeclampsia; $\mathrm{SD}=$ Standard Deviation

Table 5: the labor outcomes of both groups.

\begin{tabular}{|l|l|l|l|}
\hline Labor outcomes & Aspirin group & Non-aspirin group & P-values \\
\hline NVD & $12(48 \%)$ & $9(36 \%)$ & $<0.001$ \\
\hline C/S & $13(52 \%)$ & $16(64 \%)$ & $<0.001$ \\
\hline
\end{tabular}

$\mathrm{C} / \mathrm{S}=$ Cesarean Section; NVD = Normal Vaginal Delivery

\section{DISCUSSION}

Preeclampsia is a serious disease for the health of the mothers and their babies, and low dose of aspirin during pregnancy may prevent it. There is no evidence of an increased incidence of low birth weight, intrauterine growth restriction (IUGR) or prematurity following low dose aspirin exposure in utero. Moreover, a meta-analysis suggested that initiation of treatment with low dose aspirin before 16 weeks of gestation in women at risk of preeclampsia may have a protective effect on the incidence of IUGR, preterm delivery and perinatal death [19]. Furthermore, no studies that investigated the incidence of low birth weight, IUGR or prematurity were studied maternal aspirin use at or after 16 weeks of gestation without any current or previous risk factors. Therefore, we performed a randomized clinical trial on pregnant women with low risk factors.

A study showed that early initiation of aspirin (at 16 weeks of gestation) has a more pronounced effect on reducing preeclampsia and IUGR as compared with studies that initiated aspirin at a later time during pregnancy [20]. The administration of $100 \mathrm{mg}$ per day from aspirin during 16-36 weeks of gestation in our study was associated with significantly lower incidence of preeclampsia (Table 2). In addition, there were significant differences between the groups regarding other pregnancy complication, or adverse fetal or neonatal outcome (Table 2 and 4).

The current study failed to observe medium to large effects of aspirin on trophoblastic flow resistance in women with evidence of defective invasion at first trimester of pregnancy as determined by an abnormal uterine artery Doppler PI and RI (Table 3). In our study, we could identify women at risk for the development of preeclampsia by detecting abnormal uterine artery Doppler indices (high RI or the presence of diastolic notch either bilateral or unilateral) between 16-24 weeks of gestation. In addition, we also found a significant reduction in the occurrence of preeclampsia by giving low dose of aspirin (Table 3).

The current results showed significant impact of low dose aspirin therapy on IUGR (Table 2) and the birth weight (Table 4). A multicenter randomized controlled trial showed that there was no justification for screening with uterine artery Doppler in a low risk population [21]. Furthermore, a study on low risk women at 11-14 weeks of gestation demonstrated bilateral notching in 55\% and they concluded that it is unlikely for uterine artery Doppler to be useful for the screening of pregnancy complications [22]. However, if we only selected high risk pregnant women, the results may be different, but when we compared our results with that in the literature, we found considerable disparities. The latter may be attributed to many factors like the time of recruitment of the patients (at 16 weeks of gestation or higher) and the low risk level of the pregnant women.

Among five randomized trials [7, 9-10, 15-16] that evaluated the use of aspirin therapy in high risk patients, four of them [7, 9, 10, 16] showed a tendency toward beneficial effects although the sample size was small in three of them [7, 9, 16]. Moreover, a meta-analysis of aspirin therapy on preventing preeclampsia following uterine artery Doppler study in the second trimester also showed beneficial results [23]. Vainio et al. studied uterine artery by Doppler study as early as 12-14 weeks of 
gestation and they found that it is a useful method to depend on [24]. Furthermore, Harrington et al. in two studies [25-26] showed that there were differences in uterine and umbilical artery Doppler blood flow indices at 12-16 weeks of gestation, and bilateral notching was associated with a 22-fold increase in the odds of developing preeclampsia.

The problems with most Doppler screening study is its low positive predictive values and as gestational age advances, the specificity and positive predictive value increases significantly, but the sensitivity decreases [27]. In our study, we preferred to postpone the study of the uterine artery to at or after 16 weeks of gestation because we believed that placental implantations will be completed by 14-18 weeks of gestation as shown in other studies [28-29]. Thus, the expected changes in the uterine artery (from high resistant to a low resistant) would occur within this period and not before. By this, we can have a better selection of the patients and an increase in the specificity of the screening test.

\section{CONCLUSION}

Doppler study of the uterine artery at 16 weeks of gestation or higher in low risk pregnant women appears to be useful as a screening test for preeclampsia and IUGR. Additionally, commencing low dose aspirin therapy for such patients in their early stage of pregnancy will decrease the incidence of severe preeclampsia and also delays its onset. The impact of aspirin therapy on reducing or eliminating the possibility of IUGR is questionable, therefore, this test and aspirin therapy combination should now be considered in clinical practice for low risk pregnant women too.

\section{REFERENCES}

[1] P. Patrignani, P. Filabozzi, C. Patrono. "Selective Cumulative Inhibition of Platelet Thromboxane Production by Low-dose Aspirin in Healthy Subjects," Journal of Clinical Investigation, Vol. 69, pp. 1366-1372, 1982.

[2] M. H. F. Sullivan, A. Zosmer, R. P. Gleeson, M. G. Elder. " Equivalent Inhibition of in vivo Platelet Function by Low Dose and High Dose Aspirin Treatment," Prostaghdins, Leukotrienes and Essential Fatty Acids, Vol. 39, pp. 319-321, 1990.

[3] L. Duley. "Pre-eclampsia and the hypertensive disorders of pregnancy," British medical bulletin, Vol. 67, pp. 161-176, 2003.

[4] I. Cetin, B. Huppertz, G. Burton et al. " Pregenesys pre-eclampsia markers consensus meeting: What do we require from markers, risk assessment and model systems to tailor preventive strategies?" Placenta, Vol. 32, pp. S4-S16, 2011.

[5] G. ALBAIGES, H. MISSFELDER-LOBOS, C. LEES, M. PARRA, K. H. NICOLAIDES. "One-Stage Screening for Pregnancy Complications by Color Doppler Assessment of the Uterine Arteries at 23 Weeks' Gestation," Obstetrics \& Gynecology, VOL. 96, NO. 4, pp. 559-564, Oct. 2000.

[6] A. M. Martin, R. Bindra, P. Curcio, S. Cicero, K. H. Nicolaides. "Screening for pre-eclampsia and fetal growth restriction by uterine artery Doppler at 11-14 weeks of gestation," Obstetrics \& Gynecology, Vol. 18, NO. 6, pp. 583-586, Dec. 2001.

[7] J. A. G. Alves, B. Y. D. C. Silva, P. C. P. D. Sousa, S. B. Maia, F. D. S. Costa. "Reference range of uterine artery Doppler parameters between the 11th and 14th pregnancy weeks in a population sample from Northeast Brazil," Revista Brasileira de Ginecologia $e$ Obstetr'icia. vol. 35, NO. 8, 2013.

[8] O. Gomez, F. Figueras, S. Fernandez et al. "Reference ranges for uterine artery mean pulsatility index at 11-41 weeks of gestation," Ultrasound in Obstetrics \& Gynecology, Vol. 32, NO. 2, pp. 128132, 2008.

[9] J. Lefebvre, S. Demers, E. Bujold et al. "Comparison of two different sites of measurement for transabdominal uterine artery Doppler velocimetry at 11-13 weeks," Ultrasound in Obstetrics and Gynecology, Vol. 40, NO. 3, pp. 288-292, 2012.

[10] B. M. Sibai, R. Mirro, C.M. Chesney, C. Leffler. "Low-dose aspirin in pregnancy," Obstetrics \& Gynecology. Vol. 74, pp. 551-557, 1989.

[11] Italian study of aspirin in pregnancy. "Low-dose aspirin in prevention and treatment of intrauterine growth retardation and pregnancy-induced hypertension," Lancet. Vol. 341, pp. 396-400, 1993.

[12] S. Caritis, B. Sibai, J. Hauth et al. "Low-Dose Aspirin to Prevent Preeclampsia in Women at High Risk," N Engl J Med, Vol. 338, pp. 701-705, 1998.

[13] C. K. H. Yu, A. T. Papageorghiou, M. Parra, R. Palma Dias, K. H. Nicolaides. "Randomized controlled trial using low-dose aspirin in the prevention of pre-eclampsia in women with abnormal uterine artery Doppler at 23 weeks' gestation," Ultrasound in Obstetrics and Gynecology, Vol. 22, pp. 233239, 2003.

[14] H. Schulman, A. Fleischer, G. Farmakides et al. "Development of uterine artery compliance in pregnancy as detected by Doppler ultrasound," American Journal of Obstetrics \& Gynecology, Vol. 155, pp. 1031-1036, 1986.

[15] A. T. Papageorghiou, C. K.H. Yu, I. E. Erasmus, H. S. Cuckle, K. H. Nicolaides."Assessment of risk for the development of pre-eclampsia by maternal characteristics and uterine artery Doppler," BJOG: an International Journal of Obstetrics and Gynaecology, Vol. 112, pp. 703-709, 2005.

[16] S. Bower, S. Bewley, S. Campbell. "Improved prediction of preeclampsia by two-stage screening of uterine arteries using the early diastolic notch and color Doppler imaging," Obstetrics \& Gynecology, Vol. 82, pp. 78-83, 1993.

[17] C. Lees. "Uterine artery Doppler: time to establish the ground rules," Ultrasound in Obstetrics and Gynecology, Vol. 16, pp. 607-609, 2000.

[18] P. F. Chien, N. Arnott, A. Gordon, P. Owen, K. Khon. "How useful is uterine artery Doppler flow velcimetryin the prediction of preeclampsia, intrauterine growth retardation and perinatal death? An overview," BJOG: an International Journal of Obstetrics and Gynaecology, Vol. 107, pp. 196208, 2000.

[19] A. Benigni, G. Gregorini, T. Frusca, et al. "Effect of low-dose aspirin on fetal and maternal generation of thromboxane by platelets in women at risk for pregnancy-induced hypertension," N Engl J Med. Vol. 321, pp. 357-362, 1989.

[20] F. Goffinet, D. Aboulker, J. Paris-Llado, et al. "Screening with a uterine Doppler in low risk pregnant women followed by low dose aspirin in women with abnormal results: a multicenter randomized controlled trial," BJOG. Vol. 108, pp. 510-518, 2001.

[21] P. F. Chien, N. Arnott, A. Gordon, P. Owen, K. S. Khan. "How useful is uterine artery Doppler flow velocimetry in the prediction of pre-eclampsia, intrauterine growth retardation and perinatal death? An overview," BJOG. Vol. 107, pp. 196-208, 2000.

[22] A. M. Martin, R. Bindra, P. Curcio, S. Cicero, K. H. Nicolaides. "Screening for pre-eclampsia and fetal growth restriction by uterine artery Doppler at 11-14 weeks of gestation," Ultrasound Obstet Gynecol. Vol. 18, pp. 583586,2001

[23] A. Coomarasamy, S. Papaioannou, H. Gee, K. S. Khan. "Aspirin for the prevention of preeclampsia in women with abnormal uterine artery Doppler: a meta-analysis," Obstetrics \& Gynecology. Vol. 98 (5 Pt 1), pp. 861-866, 2001.

[24] M. Vainio, E. Kujansuu, M. Iso-Mustajarvi, J. Maenpaa. "Low dose acetylsalicylic acid in prevention of pregnancy-induced hypertension and intrauterine growth retardation in women with bilateral uterine artery notches," BJOG. Vol. 109, pp. 161-167, 2002.

[25] K. Harrington, R. G. Carpenter, C. Goldfrad, S. Campbell. "Transvaginal Doppler ultrasound of the uteroplacental circulation in the early prediction of pre-eclampsia and intrauterine growth retardation," Br J Obstet Gynaecol. Vol. 104, pp. 674-681, 1997.

[26] K. Harrington, D. Cooper, C. Lees, K. Hecher, S. Campbell. "Doppler ultrasound of the uterine arteries: the importance of bilateral notching in the prediction of preeclampsia, placental abruption or delivery of a small-for-gestational-age 
baby," Ultrasound Obstet Gynecol. Vol. 7, pp. 182-188, 1996.

[27] A. Antsaklis, G. Daskalakis, E. Tzortzis, S. Michalas. "The effect of gestational age and placental location on the prediction of preeclampsia by uterine artery Doppler velocimetry in low-risk nulliparous women" Ultrasound Obstet Gynecol. Vol. 16, pp. 635$639,2000$.

[28] F. De Wolf, C. De Wolf-Peeters, I. Brosens, W. B. Robertson. "The human placental bed: electron microscopic study of trophoblastic invasion of spiral arteries," Am J Obstet Gynecol. Vol. 137, pp. 58$70,1980$.

[29] T. Y. Khong, F. De Wolf, W. B Robertson, I. Brosens. "Inadequate maternal vascular response to placentation in pregnancies complicated by pre-eclampsia and by small-for-gestational age infants," Br J Obstet Gynaecol. Vol. 93, pp. 1049-1059, 1986. 